Research Article

\title{
Calcium Phosphate/Etidronate Disodium Biocement: Etidronate, Retarder or Accelerator
}

\author{
Nasim Nosoudi ${ }^{1,2}$, Amin Hasanzadeh ${ }^{3}$, Drew Holman ${ }^{2}$, Sayed Mahmood Rabiee ${ }^{4}$, Saeed Hesaraki ${ }^{5}$, \\ Fatollah Moztarzadeh $^{1,}$, , Michael Gelinsky ${ }^{6}$ \\ ${ }^{1}$ Department of Biomedical Engineering, Amirkabir University of Technology, Tehran, Iran \\ ${ }^{2}$ Department of Bioengineering, Clemson University, Clemson, South Carolina, USA \\ ${ }^{3}$ Department of Polymer Engineering, Amirkabir University of Technology, Tehran, Iran \\ ${ }^{4}$ Department of Mechanical Engineering, Babol University of Technology, Babol, Iran \\ ${ }^{5}$ Nanotechnology and Advanced Materials Department, Materials and Energy Research Center, Karaj, Iran \\ ${ }^{6}$ Centre for Translational Bone, Joint and Soft Tissue Research, University Hospital Carl Gustav Carus and Medical Faculty of \\ Technische Universität Dresden, Dresden, Germany
}

Corresponding author: E-mail: moztarzadeh@aut.ac.ir

Received: Dec. 19, 2013; Accepted: Feb. 18, 2014; Published: March 15, 2014.

Citation: Nasim Nosoudi, Amin Hasanzadeh, Drew Holman, Sayed Mahmood Rabiee, Saeed Hesaraki, Fatollah Moztarzadeh and Michael Gelinsky. Calcium Phosphate/Etidronate Disodium Biocement: Etidronate, Retarder or Accelerator. Nano Biomed. Eng. $2014,6(\mathrm{I}), 40-45$.

DOI: $10.5101 /$ nbe.v6il.p40-45.

\begin{abstract}
Bisphosphonate release from calcium phosphate cement has been investigated. We hypothesized that local delivery of bisphosphonate from the calcium phosphate cement improves the mechanical properties. Different samples with different concentration of Etidronate disodium have been made and analyzed. We observed a dual behavior from Etidronate in retarding and accelerating the setting of calcium phosphate cement in low and high concentration respectively. After soaking samples in simulated body fluid, an optimum concentration of Etidronate disodium was added to the calcium phosphate paste in order to achieve the best mechanical properties. Scanning electron microscopy (SEM) showed the formation of hydroxyapatite crystals. X-ray diffraction (XRD) analysis was used to determine hydroxyapatite peaks on the surface of the bio-cement, which confirms the hydroxyapatite formation.
\end{abstract}

Keywords: Hydroxyapatite; Calcium phosphate bone cement; Etidronate disodium; Bisphosphonates

\section{Introduction}

Calcium phosphate cements (CPC) are extremely compatible with both hard and soft tissues [1] because of the setting reaction products and apatitic formation [2]. CPCs are described by having calcium ions $\left(\mathrm{Ca}^{2+}\right)$ and any of orthophosphates ( $\left.\mathrm{PO}^{3-}\right)$, metaphosphates or pyrophosphates $\left(\mathrm{P}_{2} \mathrm{O}_{7}{ }^{4-}\right)[3,4]$. CPCs are a mixture of calcium phosphate minerals and a liquid part that could be an organic acid or water. The main and the most significant characteristics of the CPCs are their biocompatiblity and osteoconductive. These properties have contributed to their extensive use in the in treatment of bone defects [5]. CPC is bioactive, but more interestingly, tricalcium phosphate is resorbable [6]. It allows for new bone formation around the defect as the cement is resorbed [4].

The defect is filled by the paste as a substitute 
for the injured part of bone or for fixing another implant [7]. The first transformation of this paste is after mixing with an aqueous phase and right before placing it into a defect [8]. This is known as the initial setting (hardening). The final setting is the process of hardening while exposed to the bodily environment and phase transformation reaction based on dissolutionprecipitation [9]. CPCs commonly are classified into two groups based on their hardening reaction: an acid-base reaction or hydrolysis of defined amount of calcium phosphates [10].

It is well-known that nanostructured CPCs, for example nano-sized needle-like hydroxyapatite, can improve the sintering kinetics because of their greater surface area that causes a significant enhancement in mechanical properties [11].

Different types of drugs have been loaded in CPCs since they are possible matrixes for loading different types of drugs and deliver them locally [12]. Bisphosphonates are prescribed for osteoclastmediated diseases such as osteoporosis, and Paget disease. They are analogous to pyrophosphate wherein the bond of P-O-P has been substituted with a nonhydrolyzable bond of P-C-P [13]. The P-O-P and P-C-P chelate divalent ions like $\mathrm{Ca}^{2+}$ with their diphosphate group In the same way, they can target the bone [14]. Bisphosphonates (BPs) are known as antiresorptive drugs usually used to prevent bone resorption. However, the latest research shows that BPs are important for enhancing bone microarchitecture [15].

In the current study, we have tested a hypothesis that the combination of Bisphosphonates and calcium phosphate cements (CPCs) produce formulations with controlled setting, and mechanical properties for orthopedic uses.

\section{Materials and Methods}

\section{Sample preparation}

The $\beta$-TCP was made by heating the combination of 2 moles of dicalcium phosphate anhydrous (DCPA, Merck No. 2144) and 1 mole of calcium carbonate ( $\mathrm{CaCO}_{3}$, Merck No. 2069).

The cement powder was prepared by mixing $\beta$-TCP, DCPA and $\mathrm{CaCO}_{3}$ thoroughly $(70,25,5$ ratio respectively). To prepare every 2 cement samples, 2 $\mathrm{mg}$ of CPC powder was mixed with $1 \mathrm{~mL}$ of DI water, so that the powder-to-liquid ratio was 0.5 . The amount of liquid was minimal for workability. After mixing for 30 seconds, the paste was loaded into a plastic mold by spatula. The setting times were measured using a Gillmor needle. In the drug loaded group, Etidronate was loaded in a matrix of calcium phosphate cement. 10 to $50 \mu \mathrm{g}$ of Etidronate powder (Modava Farmaco, Iran) was mixed with powder part of the cement. The setting time measurements were done as previously described. Names of the samples used in this paper are shown in Table 1.

Table 1 Samples abbreviation

\begin{tabular}{cc}
\hline Sample & Specification \\
\hline W0 & No Etidronate \\
W5 & $+5 \mu \mathrm{g}$ Etidronate per sample \\
W10 & $+10 \mu \mathrm{g}$ Etidronate \\
W15 & $+15 \mu \mathrm{g}$ Etidronate \\
W20 & $+20 \mu \mathrm{g}$ Etidronate \\
W25 & $+25 \mu \mathrm{g}$ Etidronate \\
W30 & $+30 \mu \mathrm{g}$ Etidronate \\
W35 & $+35 \mu \mathrm{g}$ Etidronate \\
W40 & $+40 \mu \mathrm{g}$ Etidronate \\
W45 & $+45 \mu \mathrm{g}$ Etidronate \\
W50 & $+50 \mu \mathrm{g}$ Etidronate* \\
\hline
\end{tabular}

*Per sample of cement (1 mg of powder part).

\section{Initial and second setting time}

The initial setting time of the CPCs was studied in a humid chamber at $37^{\circ} \mathrm{C}$ and $90 \%$ humidity using a Gillmor needle test with a needle weight of 113.5 $\mathrm{g}$ and tip diameter of $2.1 \mathrm{~mm}$ according to ASTM C266-99-A standard. Five samples of each compound were tested. The paste was considered the initial setting when the needle did not form a visible trace onto the sample surface. The final setting time of the CPCs was recorded in a humid chamber at $37^{\circ} \mathrm{C}$ and $90 \%$ humidity using a Gillmor needle test with a needle weight of $453.6 \mathrm{~g}$ and tip diameter of $1.06 \mathrm{~mm}$ according to ASTM C266-99-A standard. The final setting of the paste was defined as when the needle did not leave a visible trace on the sample.

\section{X-ray diffraction (XRD) analysis}

The present phases of the cement were characterized by powder X-ray diffraction method using a Philips 3710-MPD control equipped with $\mathrm{Cu} \mathrm{K \alpha}$ radiation. Data were collected from $2 \theta=20^{\circ}-70^{\circ}$ with a step size of $0.02 \% \mathrm{sec}$ and a normalized count time of $1 \mathrm{~s} /$ step. For phase detection in the samples after SBF incubation at the defined time points, samples were 
first rinsed with distilled water, dried, ground to fine powder, weighted and then characterized.

\section{Statistical analysis}

One-way and two-way ANOVA statistical analysis was used to estimate the statistical significance of the data. In all cases, the results were considered statistically different $\mathrm{p}$-value $<0.05$.

\section{Scanning electron microscopy (SEM)}

The microstructure of the samples was observed by scanning electron microscopy (Philips, XL30). Sample surfaces were coated with a thin layer of gold. Energy dispersive spectroscopy (EDS) was used to determine the $\mathrm{Ca} / \mathrm{P}$ ratio of the cement.

\section{Etidronate disodium release}

Samples of each concentration were placed in 10 $\mathrm{mL}$ (for each) of simulated body fluid (SBF). The simulated body fluid (SBF) consisted of $8.00 \mathrm{~g} \mathrm{NaCl}$, $0.35 \mathrm{~g} \mathrm{NaHCO}_{3}, 0.40 \mathrm{~g} \mathrm{KCl}, 0.06 \mathrm{~g} \mathrm{KH}_{2} \mathrm{PO}_{4}, 0.10 \mathrm{~g}$ $\mathrm{MgCl}_{2} \cdot 6 \mathrm{H}_{2} \mathrm{O}, 0.14 \mathrm{~g} \mathrm{CaCl}_{2}, 0.06 \mathrm{~g} \mathrm{Na}_{2} \mathrm{HPO}_{4} \cdot 2 \mathrm{H}_{2} \mathrm{O}$, $0.06 \mathrm{~g} \mathrm{MgSO}_{4} \cdot 7 \mathrm{H}_{2} \mathrm{O}$ and $1.00 \mathrm{~g}$ glucose in $1000 \mathrm{~mL}$ distilled $\mathrm{H}_{2} \mathrm{O}$ and was buffered to $\mathrm{pH}$ 7.4. The samples were kept at $37^{\circ} \mathrm{C}$ in a water bath. Three samples were removed after 1, 7, 14, and 21 days. Etidronate concentration released into the solution was measured by total phosphorus analysis per ASTM D6501-99.

\section{Mechanical testing}

After setting, five cement samples were collected, washed and dried. The compressive strength of the wet sample was measured at a cross head speed of $1 \mathrm{~mm} /$ min using a Zwick/Roell Universal Testing Machine. The same measurement was done for five samples after 1 and 7 days incubation in SBF.

\section{Results}

\section{Setting Time}

The setting time of the cement with various Etidronate disodium concentrations are presented in Figure 1. The initial and final setting times were defined as a function of the Etidronate disodium concentration. Results show that the initial and final setting times increased with Etidronate concentration increment then fall down again.

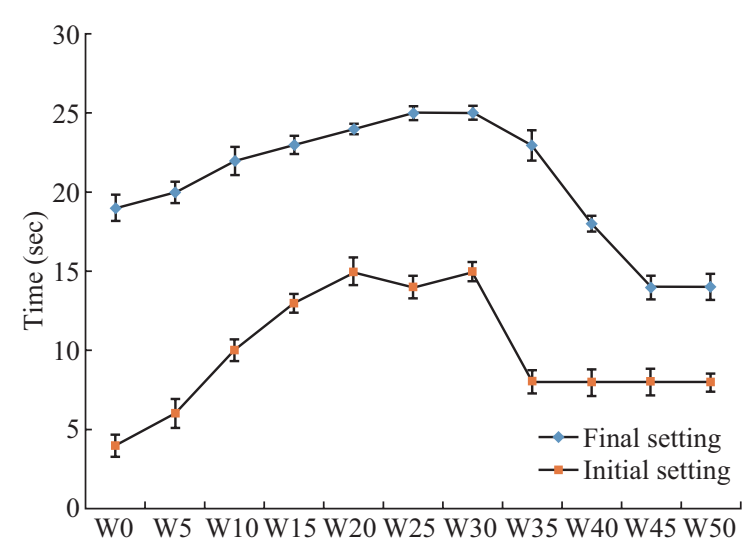

Fig. 1 Initial and final setting of cement containing Etidronate. Each bar represents the mean \pm standard deviation of at least three independent experiments.

\section{X-ray diffraction (XRD) analysis}

TThe drug is amorphous and no crystalline peaks were observed in X-ray diffraction. Figure 2 shows a wide region in the spectrum between $30^{\circ}$ and $35^{\circ}$, which become more distinct in samples after 14 days incubation that shows the CPC to apatite transformation. Comparing W10 and W50 in D1, lower Etidronate concentration shows more apatite formation, while after 14 days incubation in SBF higher Etidronate aids apatite formation.

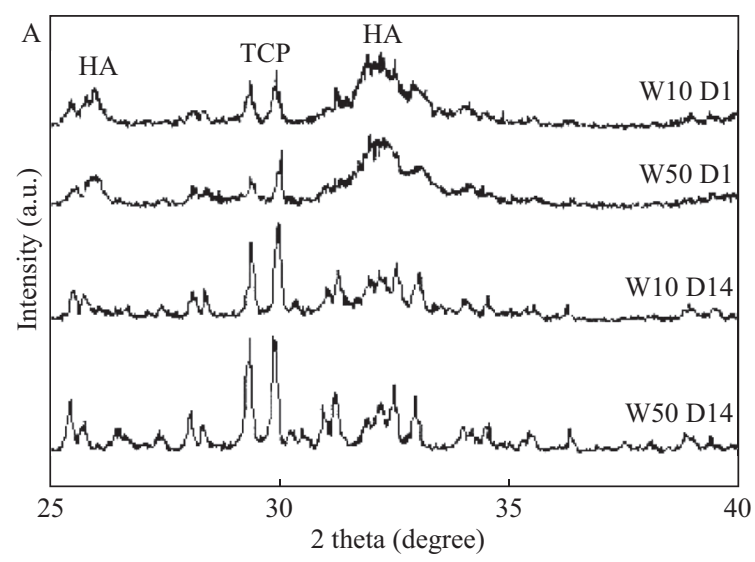

Fig. 2 XRD of W10 \& W50 after one and fourteen days.

\section{Drug release}

Figure 3 shows in vitro release of Etidronate into the SBF solution. The released drug in most of the samples with different drug concentration is about $39 \%$, while the highest release after 21 days belongs to sample with $35 \mu \mathrm{g}$ drug.

\section{Compressive Strength}

Table 2 shows the compressive strength of cement 

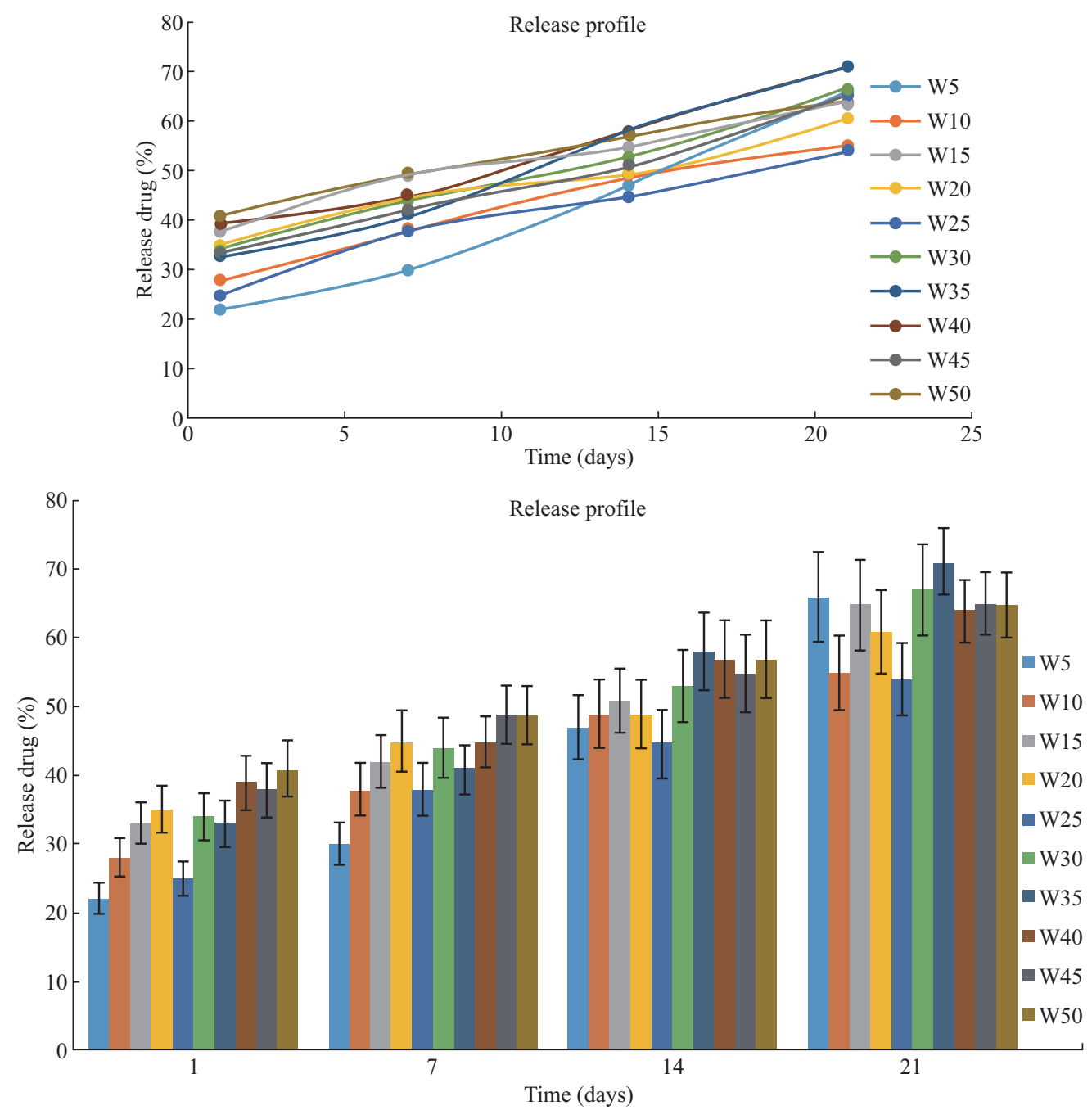

Fig. 3 Release profile.

in different concentrations of Etidronate. At all the concentrations, samples from D1 and D7 were taken and analyzed. The compressive strength values of reference calcium phosphate cement (W0) were higher than that of other cements (+Etidronate) at D1. When comparing the effect of incubation time on the compressive strength of the individual cements, the compressive strength of all samples are significantly higher than D1.

The best value of compressive strength belongs to W35 sample after 7 days and data show that increasing Etidronate more than $35 \mu \mathrm{g}$ causes a significant decrease in the compressive strength.

\section{Scanning electron microscopy (SEM)}

The SEM (scanning electron microscopy) micrograph is given in Figure 4. The SEM images were obtained for different durations ( $2 \mathrm{~h}, 4,6$ and 7 days) of incubation in SBF to monitor the mineralization of apatite-like materials on the nanofiber surfaces. Rod- like hydroxyapatite with a length of approximately 1 $\mu \mathrm{m}$ were formed after 21 days incubation.

\section{Discussion}

This study was designed to develop a drug carrier model using CPC for bone resorption inhibitors. The cement was loaded with Etidronate disodium, which is used in osteoporosis and Paget diseases. A release profile was sustained and deepens on initial drug loading. Based on setting time and mechanical properties data, Etidronate can be an effective agent to control the other CPC properties like setting time and strength.

The initial hardening of calcium phosphate cement is a result of chelation of calcium or acid base reaction, and the final hardening is the transformation of the components of the cements to hydroxyapatite [3]. Initial and final setting showed a constant increase in initial setting until a maximum is reached. After this 
Table 2 Effect of Etidronate content on the compressive strength of cement. All values are reported as the mean \pm standard deviation of at least three independent experiments. \#, significantly different from W0 (paired by time course, twoway ANOVA, $P<0.05)$

\begin{tabular}{cccc}
\hline Sample & Specification & $\begin{array}{c}\text { Compressive strength (MPa) } \\
\text { before soaking in SBF }\end{array}$ & $\begin{array}{c}\text { Compressive strength (MPa) } \\
\text { after soaking in SBF(D7) }\end{array}$ \\
\hline W0 & Pure cement matrix & $20.36 \pm 3.4$ & $24.67 \pm 2.9$ \\
W5 & $+5 \mu \mathrm{g}$ Etidronate & $19.86 \pm 1.2$ & $21.09 \pm 1.1^{\#}$ \\
W10 & $+10 \mu \mathrm{g}$ Etidronate & $16.37 \pm 2.1$ & $21.78 \pm 2.3$ \\
W15 & $+15 \mu \mathrm{g}$ Etidronate & $13.42 \pm 0.9^{\#}$ & $22.43 \pm 2.3$ \\
W20 & $+20 \mu \mathrm{g}$ Etidronate & $17.56 \pm 1.5$ & $24.44 \pm 1.9$ \\
W25 & $+25 \mu \mathrm{g}$ Etidronate & $20.98 \pm 1.8$ & $24.12 \pm 2.2$ \\
W30 & $+30 \mu \mathrm{g}$ Etidronate & $21.45 \pm 2.9$ & $25.17 \pm 2.6$ \\
W35 & $+35 \mu \mathrm{g}$ Etidronate & $19.56 \pm 1.3$ & $27.04 \pm 3.2^{\#}$ \\
W40 & $+40 \mu \mathrm{g}$ Etidronate & $16.78 \pm 1.7^{\#}$ & $26.03 \pm 3.1$ \\
W45 & $+45 \mu \mathrm{g}$ Etidronate & $13.98 \pm 1.1^{\#}$ & $22.16 \pm 2.1$ \\
W50 & $+50 \mu \mathrm{g}$ Etidronate & $14.49 \pm 1.4$ & $19.31 \pm 4.7$ \\
\hline
\end{tabular}
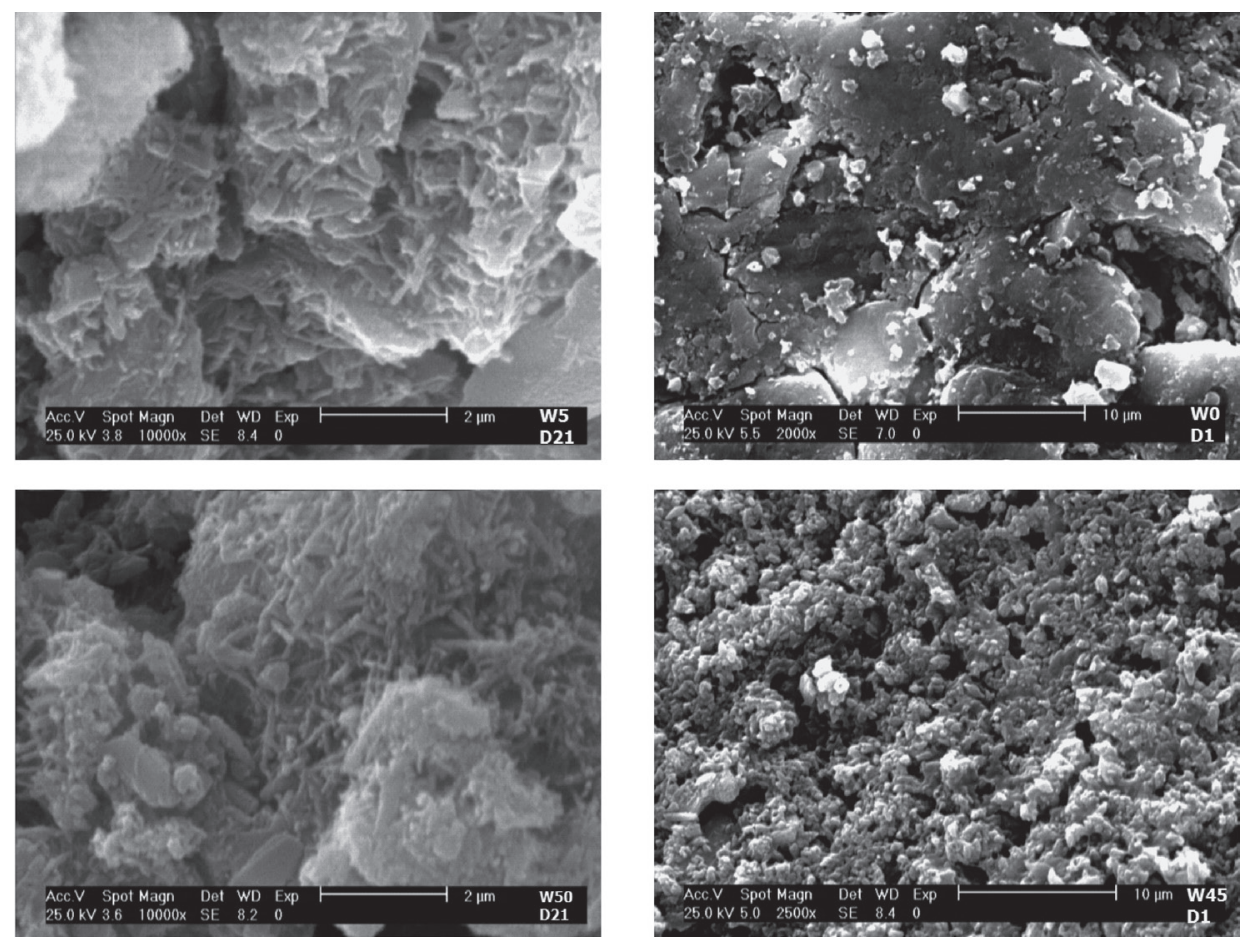

Fig. 4 SEM images of W5 and W50 after 21 days; W0 and W45 after one day, incubation in SBF.

maximum, stetting time decreases until it levels off to a constant setting time.

Increasing Etidronate causes a constant increase in initial setting time until it reaches a maximum and the reason is behind the $\mathrm{Ca}^{2+}$ chelation by Etidronate that causes a delay in the initial setting. It makes the initial setting profile split into two zones. In low concentration of Etidronate, chelation is governing the reaction. However, the ability to chelate $\mathrm{Ca}^{2+}$ will be reduced at an acidic $\mathrm{pH}$ [16]. Increasing the Etidronate concentration decreases the $\mathrm{pH}$ and then acid base reaction is governing the initial setting time that is shown as a negative slope region (second zone). Based on the XRD results, in W50 D1, less apatite is formed compared to the W10 D1. However, after 14 days, apatite content in W50 is higher than W10. Etidronate occupies the active sites so that high Etidronate content samples in early stages show less apatite formation, while in long term, Etidronate release facilitates the apatite formation.

Etidronate content affects the drug release profile and release is acting in a linear manner between first and seventh day, but after 21 days the release profile is not linear. As it was shown, within the used concentration range, 50\%-70\% Etidronate was released over 21 days of soaking in SBF that suggests to use this composite as a sustained release substrate, while drug release from a CPC matrix is a diffusion-controlled 
process [17]. Figure 3 shows the fraction of released Etidronate against time for the studied samples. All samples showed a linear trend within the 21 days, except for W5. A linear model is compatible with the Tung model for drug release [18]. At this stage, the degradation of CPC matrix plays an important role in the release process.

Compressive strength is affected by hydroxyapatite formation. Hardening is dependent on the apatite formation, which is affected by the presence of molecules and adsorption or desorption in active sites. If the other molecules occupy the active sites then the apatite formation is retarded. Results show that the lowest concentration of Etidronate, has significantly lower compressive strength compared to the control, which means less apatite is formed before soaking in SBF. Mechanical properties of W35 are significantly higher than the reference cement after soaking in SBF and exposure to the bodily environment. Under this condition, hydroxyapatite is more likely to be formed.

\section{Conclusion}

CPCs are potential matrixes for loading different types of drugs because of ability to have controlled and time dependent release. The effective amount of drug still needs to be studied. For this cement system, the CPC containing $35 \mu \mathrm{g}$ Etidronate showed low early strength, but high strength after soaking in SBF. Suitable setting time and mechanical properties along with sustained release make this combination a suitable choice for bone repair and bone reconstruction.

\section{References}

[1] Link D. P., Van Den Dolder J., Jurgens W. J. F. M., Wolke J. G. C., Jansen J. A., Mechanical evaluation of implanted calcium phosphate cement incorporated with PLGA microparticles. Biomaterials, 2006. 27(28): p. 4941-4947.

[2] Medvecky L., Stulajterova R., The Hardening Process and Mechanical Properties of Calcium Phosphate Cement by Application of KH2 PO4 -H3 PO4 Hardening Liquid. Powder Metallurgy Progress, 2008. 8(4): p. 362366.

[3] Chow, L. C., Next generation calcium phosphate-based biomaterials. Dent. Mater. J. Dental Materials Journal, 2009. 28(1): p. 1-10.

[4] Hesaraki S., Moztarzadeh F., Sharifi D., Formation of interconnected macropores in apatitic calcium phosphate bone cement with the use of an effervescent additive. Journal of biomedical materials research. Part A, 2007. 83(1): p. 80-7.

[5] Offer L.,Veigel B., Pavlidis T., Heiss C., Gelinsky M.,
Reinstorf A., Wenisch S. ,Lips K. S., Schnettler R., Phosphoserine-modified calcium phosphate cements: bioresorption and substitution. Journal of tissue engineering and regenerative medicine, 2011. 5(1): p. 119.

[6] Cao W. H. L. L., Bioactive materials. Ceramics International Ceramics International, 1996. 22(6): p. 493507.

[7] Burdick J. A., Mauck R. L. Biomaterials for tissue engineering applications a review of the past and future trends. 2011.

[8] Dorozhkin S., Self-Setting Calcium Orthophosphate Formulations. JFB Journal of Functional Biomaterials, 2013. 4(4): p. 209-311.

[9] Ishikawa K., Bone substitute fabrication based on dissolution-precipitation reactions. Mater. Materials, 2010. 3(2): p. 1138-1155.

[10] Sakamoto K, Nomoto T., Yamaguchi S., Fujihara I., Satoh K., Ichihara J., Kimura T., Tsunawaki Y., Bone cements based on ground \&\#x03B2;-tricalcium phosphate with sufficient compressive strengths and short hardening time. J Ceram Soc Jpn Nippon Seramikkusu Kyokai Gakujutsu Ronbunshi/Journal of the Ceramic Society of Japan, 2013. 121(1416): p. 714-722.

[11] Rezvannia M., Moztarzadeh F., Tahriri M., Formation of hydroxyapatite nanoneedles on the surface of a novel calcium phosphate/blood plasma proteins biocement in simulated body fluid (SBF). J. Ceram. Process. Res. Journal of Ceramic Processing Research, 2009. 10(5): p. 669-673.

[12] Hesaraki S., Nemati R., Nosoudi N., Preparation and characterisation of porous calcium phosphate bone cement as antibiotic carrier. Adv. Appl. Ceram. Advances in Applied Ceramics, 2009. 108(4): p. 231-240.

[13] Morris Cd, Einhorn T. A., Bisphosphonates in orthopaedic surgery. The Journal of bone and joint surgery. American volume, 2005. 87(7): p. 1609-18.

[14] Drake, M. T., Cremers, S. C. L. M., Bisphosphonate therapeutics in bone disease: The hard and soft data on osteoclast inhibition. Mol. Interventions Molecular Interventions, 2010. 10(3): p. 141-152.

[15] Matuszewski L, Turzanska K., Matuszewska A., Jablonski M., Polkowska I., Mazurkiewicz T., Effect of implanted bisphosphonate-enriched cement on the trabecular microarchitecture of bone in a rat model using microcomputed tomography. International orthopaedics, 2013. 37(6): p. 1187-93.

[16] Rogers, M. J., Gordon S., Benford H. L., Coxon F. P., Luckman S. P., Monkkonen J., Frith J. C., Cellular and Molecular Mechanisms of Action of Bisphosphonates. CANCER -PHILADELPHIA-, 2000. 89: p. 2961-2978.

[17] Ginebra, M. P., Traykova T., Planell J. A., Calcium phosphate cements: Competitive drug carriers for the musculoskeletal system? Biomaterials, 2006. 27(10): p. 2171-2177.

[18] Tung, I. C., In vitro drug release of antibiotic-loaded porous hydroxyapatite cement. Artificial cells, blood substitutes, and immobilization biotechnology, 1995. 23(1): p. 81-8.

Copyright $(2014$ Nasim Nosoudi, Amin Hasanzadeh, Drew Holman, Sayed Mahmood Rabiee, Saeed Hesaraki, Fatollah Moztarzadeh and Michael Gelinsky. This is an open-access article distributed under the terms of the Creative Commons Attribution License, which permits unrestricted use, distribution, and reproduction in any medium, provided the original author and source are credited. 